\title{
Produção de pimentão em ambiente protegido com água residuária
}

\section{Production of pepper in protected environment with waste water}

\author{
Pedro Henrique Máximo de Souza Carvalho ${ }^{1}{ }^{1}$; Jamerson da Silva e Silva ${ }^{\left(D^{2}\right.}$; Rodrigo Rafael Da Silva (D) $^{3}$; \\ William Ralf Santos Costa ${ }^{4}$; Sérgio Oliveira Pinto de Queiroz ${ }^{5}{ }^{5}$ Ruy de Carvalho Rocha ${ }^{6}$
}

${ }^{1}$ Graduando em Engenharia Agronômica pela Universidade do Estado da Bahia, Juazeiro, Bahia; (87) 999727737, pedrocarvalho2008@ hotmail.com; ${ }^{2}$ Graduando em Engenharia Agronômica pela Universidade do Estado da Bahia, Juazeiro; (74) 999818279, jamersonsilva28@ gmail.com; ${ }^{3}$ Mestrando no programa de manejo de água e solo, Universidade Federal Rural do Semiárido, Mossoró, Rio Grande do Norte; (87) 999422772, rodrigosilva rafael@ @otmail.com; ${ }^{4}$ Engenheiro Agrônomo, graduado na Universidade do Estado da Bahia, Juazeiro; (74) 988190250, ralfw20@ gmail.com; ${ }^{5}$ Professor e pesquisador da Universidade do Estado da Bahia, Juazeiro; sopqueiroz@gmail.com; ${ }^{6}$ Professor e pesquisador da Universidade do Estado da Bahia, Juazeiro; ruycarvalhorocha@ gmail.com.

A R T I G O

Recebido: 01/11/2018

Aprovado: 23/05/2019

\section{Palavras-chave:}

Capsicum annuum

Manejo de água

Reúso de água

\section{Key words:}

Capsicum annuum

Water management

Water reuse.

\begin{abstract}
R E S U M O
Objetivou-se estudar o desempenho agronômico do pimentão cv. Ikeda, irrigado com diferentes qualidades de água, sob dois métodos de manejos de irrigação: reflectometria no domínio da frequência e tensiometria, sob ambiente protegido. $\mathrm{O}$ delineamento estatístico utilizado foi o inteiramente casualizado, em esquema de parcelas subdivididas, constituído de três qualidades de água nas parcelas, e dois manejos de irrigação nas subparcelas. Foram avaliadas a produtividade total; produtividade comercial; eficiência do uso da água; massa média dos frutos; comprimento; diâmetro; relação comprimento/diâmetro; teor de sólidos solúveis; acidez titulável e $\mathrm{pH}$. Os resultados obtidos permitem concluir que a produtividade e qualidade físicas dos frutos de pimentão não foram afetadas pela qualidade da água de irrigação, enquanto a menor demanda hídrica quantificada pela tensiometria influenciou significativamente apenas nos $\mathrm{pH}$ dos frutos.
\end{abstract}

A B S T R A C T
The objective of this study was to study the agronomic performance of chili cv. Ikeda,
irrigated with different water qualities, under two methods of irrigation management:
frequency reflectometry and tensiometry under protected environment. The statistical
design used was completely randomized, in a subdivided plots scheme, consisting of three
water qualities in the plots, and two irrigation managements in the subplots. The total
productivity was evaluated; commercial productivity; efficiency of water use; average fruit
mass; length; diameter; length/diameter ratio; soluble solids content; titratable acidity and
pH. The results obtained allow us to conclude that the productivity and physical quality of
the sweet pepper fruits were not affected by the quality of the irrigation water, while the
lower water demand quantified by the tensiometry influenced only the pH of the fruits.

\section{INTRODUÇÃO}

O pimentão (Capsicum annuum L.) se destaca como uma das olerícolas mais consumidas no Brasil, tendo uma área de produção estimada em cerca de 11.188 ha, sendo a nona hortaliça mais produzida (CNA, 2017). Seu cultivo dar-se em campo aberto ou em ambiente protegido, este último proporcionando rendimentos superiores (SANTOS, 2015), surgindo como alternativa de produção eficiente aos horticultores, tornando possível a redução da variabilidade ambiental e um melhor desenvolvimento da cultura em regiões áridas e semiáridas, resultando no aumento da produtividade e qualidade da produção (OLIVEIRA, 2012).

Nas regiões áridas e semiáridas, a disponibilidade de água de boa qualidade tornou-se um fator limitante ao desenvolvimento urbano, industrial e agrícola. Planejadores e entidades gestoras de recursos hídricos procuram, continuadamente, novas fontes de recursos para suprir a crescente demanda hídrica (SILVA, 2016).

$\mathrm{O}$ uso racional de água residuária tratada de origem doméstica, na agricultura, deve ser considerado como fonte hídrica e de nutrientes para as culturas, contribuindo com a

\section{Revista Verde}

ISSN 1981-8203

Pombal, Paraíba, Brasil

\author{
v. 14, n.3, jul.-set, p.359-365, 2019 \\ doi: $10.18378 /$ rvads.v14i3.6493
}


sustentabilidade do sistema de produção e para o controle da poluição urbana, agregando benefícios econômicos àqueles ambientais e de saúde pública (SHAER-BARBOSA et al., 2014).

A determinação de tensão no solo através de tensiômetro é a metodologia mais utilizado no campo para determinar o potencial mátrico do solo. Sua faixa de leitura atinge até $80 \mathrm{kPa}$, intervalo suficiente ao monitoramento de atividades de produção vegetal (BRITO et al., 2009).

Para Coelho et al., (2010), outras metodologias podem ser utilizadas para estimar o conteúdo de água no solo, sendo as mais usuais a medida da condutividade elétrica/térmica ou capacitância, a moderação de nêutrons, a atenuação de raios gama, a TDR (reflectometria no domínio de tempo) e a FDR (reflectometria no domínio da frequência).

De acordo com Terra (2010), a técnica da FDR oferece algumas vantagens em relação aos outros métodos, como a obtenção de um grande número de medidas de forma contínua, sem danificar a estrutura do solo, a rapidez na obtenção dos dados, a facilidade de transporte, a não emissão de radioatividade ionizante, associado ao custo mais baixo, se comparado a outras metodologias e equipamentos disponíveis. A determinação da constante dielétrica, com base na reflectometria do domínio da frequência, tem se difundido para a medição do teor volumétrico de umidade do solo, pelo fato de que a constante dielétrica da água é significativamente maior que as constantes dielétricas da matriz do solo seco e do ar (ALASADI e MOUAZEN, 2014).

O objetivo desse trabalho foi avaliar o desempenho agronômico de plantas de pimentão irrigadas com diferentes qualidades de água sob manejos de irrigação.

\section{MATERIAL E MÉTODOS}

O trabalho foi desenvolvido entre março e julho de 2018 no campo experimental da Universidade do Estado da Bahia, no
Vale do São Francisco, município de Juazeiro, Bahia, sob coordenadas geográficas $9^{\circ} 24^{\prime} \mathrm{S}$ de latitude, $40^{\circ} 30^{\prime} \mathrm{W}$ de longitude e $368 \mathrm{~m}$ de altitude, em ambiente protegido com área de $10 \mathrm{~m} \mathrm{x} 24 \mathrm{~m}$, estrutura tipo sombreiro e tela de sombreamento preta com porcentagem de sombreamento de $40 \%$.

O preparo do solo consistiu-se de aração, gradagem e da construção de canteiros com $0,50 \mathrm{~m}$ de largura e $0,15 \mathrm{~m}$ de altura. Com os canteiros finalizados, distribuiu-se uma mangueira gotejadora por canteiro e, posteriormente, adicionouse mulch em toda a área de produção.

Para obtenção das mudas da cultivar Ikeda, foi realizado o semeio em copos plásticos com volume de $300 \mathrm{~mL}$, com substrato para crescimento, até 30 dias após a semeadura (DAS), sendo posteriormente transplantadas para área experimental, onde foram dispostas em berços sob espaçamento de $0,50 \mathrm{~m}$ x $0,80 \mathrm{~m}$.

O delineamento experimental adotado foi o inteiramente casualizado, em esquema de parcelas subdivididas, tendo três qualidades de água (água do rio São Francisco acrescida de $100 \%$ da recomendação de nutrição; água residuária doméstica tratada acrescida com $50 \%$ da recomendação de nutrição; e água residuária doméstica tratada) nas parcelas e dois métodos de manejo de irrigação nas subparcelas (reflectometria no domínio da frequência, quantificado pela sonda hidrofarm e tensiometria), repetidos cinco vezes.

A água residuária foi coletada com o auxilio de uma bomba centrifuga de $0,5 \mathrm{cv}$, na lagoa de estabilização do Serviço Autônomo de Água e Esgoto - SAAE, localizado no bairro São Geraldo, município de Juazeiro, BA, e, posteriormente transportada em recipientes fechados, e estocada em duas caixas plásticas de $2000 \mathrm{~L}$, no local do experimento.

As diferentes qualidades de água foram caracterizadas quanto ao pH, RAS, CE, N, $\mathrm{K}^{+}, \mathrm{Ca}^{2+}, \mathrm{Mg}^{2+}, \mathrm{Na}^{+}, \mathrm{Cl}, \mathrm{SO} 3$, $\mathrm{HCO} 3, \mathrm{P}$ e quanto à presença de Escherichia coli, no SENAI de Petrolina - PE, como dispostos na tabela 1.

Tabela 1. Caracterização química das qualidades de água usadas na irrigação

\begin{tabular}{|c|c|c|c|}
\hline Parâmetros & $\begin{array}{c}\text { Água bruta do Rio São } \\
\text { Francisco } \\
\end{array}$ & $\begin{array}{c}\text { Efluente de lagoa de } \\
\text { estabilização }\end{array}$ & $\begin{array}{c}\text { Intervalo usual na água de } \\
\text { irrigaçãao }^{\mathrm{a}}\end{array}$ \\
\hline $\mathrm{pH}$ & 7,50 & 7,60 & $0-8,2$ \\
\hline $\operatorname{RAS}(\mathrm{mmolc} / \mathrm{L})^{1 / 2}$ & 0,10 & 4,08 & $0-15$ \\
\hline $\mathrm{CE}\left(\mathrm{dS} \mathrm{m} \mathrm{m}^{-1}\right)$ & 0,09 & 0,97 & $0-3,0$ \\
\hline $\mathrm{N}\left(\mathrm{mmol}_{\mathrm{c}} / \mathrm{L} 1\right)$ & 0,8 & 18,45 & $0-30$ \\
\hline $\mathrm{K}\left(\mathrm{mmol}_{\mathrm{c}} / \mathrm{L}\right)$ & 0,07 & 0,83 & $0-2,0$ \\
\hline $\mathrm{Ca}\left(\mathrm{mmol}_{\mathrm{c}} / \mathrm{L}\right)$ & 0,40 & 1,12 & $0-20$ \\
\hline $\mathrm{Mg}\left(\mathrm{mmol}_{\mathrm{c}} / \mathrm{L}\right)$ & 0,45 & 1,44 & $0-5,0$ \\
\hline $\mathrm{Na}\left(\mathrm{mmol}_{\mathrm{c}} / \mathrm{L}^{1}\right)$ & 0,10 & 7,30 & $0-40$ \\
\hline $\mathrm{Cl}\left(\mathrm{mmol}_{\mathrm{c}} / \mathrm{L}\right)$ & 0,10 & 0,95 & $0-30$ \\
\hline $\mathrm{SO}_{3}$ total $\left(\mathrm{mmol}_{\mathrm{c}} / \mathrm{L}\right)$ & 0,04 & 0,91 & $0-20$ \\
\hline $\mathrm{HCO}_{3}\left(\mathrm{mmol}_{\mathrm{c}} / \mathrm{L}\right)$ & 0,40 & 2,48 & $0-10$ \\
\hline $\mathrm{P}\left(\mathrm{mg} \mathrm{L}^{-1}\right)$ & 1,03 & 1,09 & $0-2,0$ \\
\hline Escherichia coli & Ausente & Ausente & \\
\hline
\end{tabular}

Fonte: adaptado do Almeida (2010)

O sistema de irrigação foi composto por três caixas plásticas de 2000 litros; três motobombas de 0,5 CV; tubo gotejador Rivulis®, com $0,50 \mathrm{~m}$ entre emissores e vazão nominal de $2 \mathrm{~L} \mathrm{~h}^{-1}$, sob pressão de serviço de $1,5 \mathrm{kgf} \mathrm{cm}^{-2}$.
Para avaliar as variações nas características químicas do solo foram realizadas análises ao início e final do experimento, na camada de $0-20 \mathrm{~cm}$ do solo. 
A determinação da reposição de água, realizada diariamente, baseou-se na umidade volumétrica do solo, obtida indiretamente por leituras com a sonda hidrofarm e tensiômetros, instalados a $0,15 \mathrm{~m}$ de profundidade, associadas à curva característica de retenção de água do solo (figura 1) e curva de calibração da sonda hidrofarm, obtidas no Laboratório de Hidráulica, Irrigação e Drenagem - HIDREN/DTCS, como descrito em Queiroz (2004). O fornecimento de nutrientes se deu através de fertirrigação, com o uso do sistema Venturi, de acordo com a fase fonológica da cultura, conforme proposto por Goto e Rossi (1997).

As variáveis analisadas foram: produtividade total (PT); produtividade comercial (PC); eficiência do uso da água (EUA); massa média dos frutos (MMF), determinado com uma balança de precisa; comprimento do fruto $(\mathrm{CF})$ e diâmetro do fruto
(DF), mensurados com auxílio de um paquímetro digital; relação comprimento/diâmetro (RCD); Sólidos solúveis (SS), obtida através de 1 gota do extrato aquoso dos frutos e determinada com auxílio do refratômetro manual sendo os resultados expressos em ${ }^{\circ}$ Brix; Potencial de hidrogênio $(\mathrm{pH})$, que foi realizado através do extrato aquoso dos frutos, com auxílio de um phmetro digital. Acidez titulável (AT), determinada através da titulação com $\mathrm{NaOH} 0,1$ mol L $\mathrm{L}^{-1}$, utilizando extrato aquoso do pimentão $(10 \mathrm{~mL})$, adicionado a 50 $\mathrm{mL}$ de água destilada e acrescentadas 3 gotas do indicador fenolftaleína. Adotaram-se as normas do CEAGESP (2018) para classificar os frutos, sendo considerada comercial aquela produção com frutos de comprimento superior a $60 \mathrm{~mm}$ de comprimento e $40 \mathrm{~mm}$ de diâmetro.

Figura 1. 1A. Calibração da sonda hidrofarm em laboratório; 1B. Curva de retenção de água no solo.
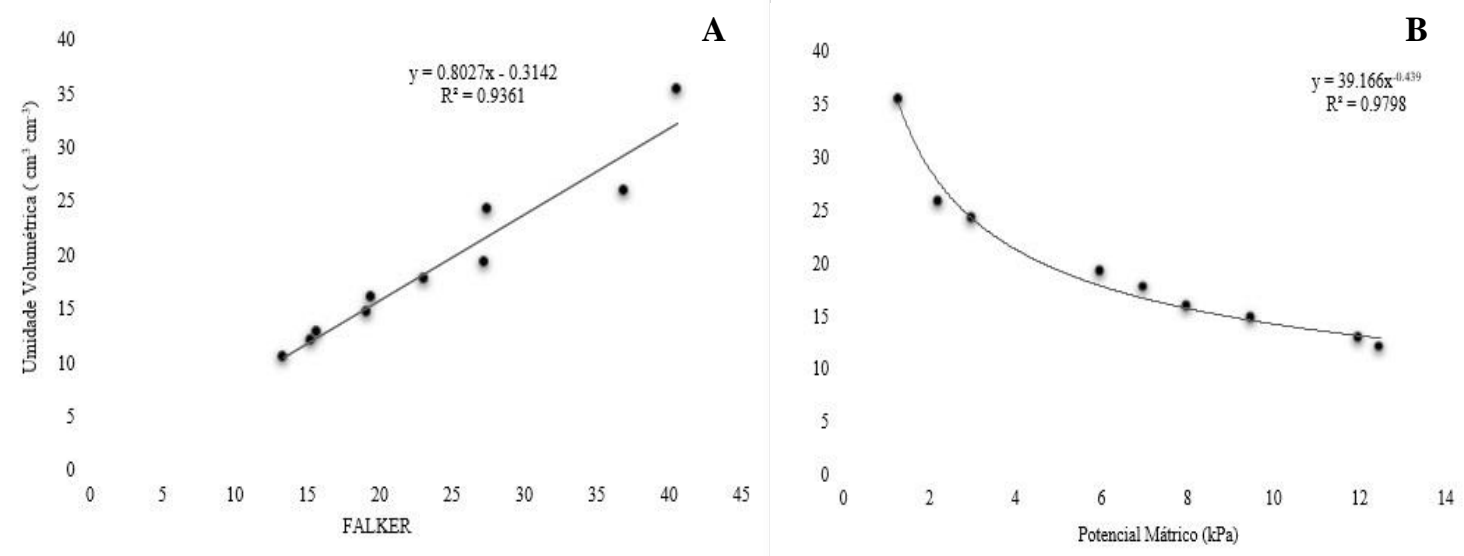

Para as avalições, foram realizadas três colheitas, a $1^{\circ}$ aos 82 dias após o plantio (DAP), a $2^{\circ}$ aos 105 DAP, e a $3^{\circ}$ aos 121 DAP, sendo colhidos todos os frutos, de acordo com o tempo de maturação do mesmo.

Aos resultados obtidos foram aplicadas análise de variância e teste de comparação de média, adotando-se Tukey a $5 \%$ de probabilidade, utilizando o programa estatístico

\section{RESULTADOS E DISCUSSÃO}

Os resultados das análises de solo, ao início e final do experimento, estão apresentados na Tabela 2. Observa-se acréscimo nas concentrações de cálcio, potássio e sódio em todos os tratamentos, ao comparar-se à condição original do solo utilizado no experimento.

ASSISTAT 7.5 (SILVA, 2008).

Tabela 2. Análise química do solo da área experimental, ao início e final do experimento, sob os três tratamentos de qualidade de água.

\begin{tabular}{|c|c|c|c|c|c|c|c|c|c|c|c|c|c|c|}
\hline Variáveis & $\mathrm{pH}$ & C.E & $\mathrm{Ca}^{+2}$ & $\mathrm{Mg}^{+2}$ & $\mathrm{~K}^{+}$ & $\mathrm{Na}^{+}$ & SB & $\mathrm{Al}^{+3}$ & $\mathrm{H}+\mathrm{Al}^{+3}$ & $\mathrm{~T}$ & V & PST & $\mathrm{P}$ & Mat. Org \\
\hline Unidades & $\mathrm{H}_{2} \mathrm{O}$ & $\left(\mathrm{dS} \mathrm{cm} \mathrm{cm}^{-1}\right)$ & & & & $(\mathrm{cmo}$ & $\mathrm{cdm} \mathrm{dm}^{-3}$ & & & & $(\%)$ & $(\%)$ & $\left(\mathrm{mg} \mathrm{dm}^{-3}\right)$ & $\left(\mathrm{g} \mathrm{kg}^{-1}\right)$ \\
\hline SCI & 5,7 & 0,02 & 2,62 & 1,81 & 0,16 & 0,04 & 4,63 & 0,0 & 0,15 & 4,78 & 96,9 & 0,83 & 58 & 5,82 \\
\hline SASF & 6,5 & 0,044 & 4,2 & 1,4 & 0,43 & 0,06 & 6,09 & 0,0 & 0,96 & 7,05 & 86,0 & 0,8 & 62 & 7,0 \\
\hline SARF & 6,6 & 0,57 & 3,5 & 1,3 & 0,30 & 0,22 & 5,31 & 0,0 & 0,96 & 6,27 & 85,0 & 3,5 & 60 & 9,0 \\
\hline SARF & 6,5 & 0,57 & 4,7 & 1,4 & 0,32 & 0,15 & 6,58 & 0,0 & 1,12 & 7,7 & 85,0 & 2,0 & 61 & 7,9 \\
\hline
\end{tabular}

SCI = solo na condição inicial; SASF = solo irrigado com água do rio São Francisco mais 100\% fertilização; SARF = solo irrigado com água residuária com $50 \%$ de fertilizante; SAR = solo irrigado com água residuária; $\mathrm{C} . \mathrm{E}=$ Condutividade elétrica; $\mathrm{T}$ - Capacidade de troca de cátions; $\mathrm{V}=\mathrm{Percentagem}$ de saturação em bases; PST = Percentagem de sódio trocável.

É importante ressaltar a elevação na concentração de sais solúveis e da porcentagem de sódio trocável próximo à zona radicular das plantas, representado pela condutividade elétrica no extrato de saturação e PST e que, apesar de não caracterizar um solo salino ou sódico, aponta para a necessidade de monitoramento da salinidade ao longo do período de aplicação da fertirrigação convencional, mas especialmente para a utilização de irrigação com água residuária no solo. Tal ferramenta pode prevenir o comprometimento da fertilidade do solo ou apontar para a necessidade de adoção de correções no 
sistema de produção, tais como implantação de sistema artificial de drenagem ou adoção de lâminas de lixiviação.

Silva (2016), comparando o uso de água de rio com efluente de lagoa de estabilização, na irrigação de melão, observou redução dos teores de cálcio e magnésio do solo, além do aumento na porcentagem de sódio trocável.

A produtividade total, considerando as três colheitas realizadas, resultou em valores médios de $21,49 \mathrm{t} \mathrm{ha}^{-1}$ para os tratamentos com aplicação da água residuária tratada doméstica e $21,23 \mathrm{t} \mathrm{ha}^{-1}$ para os tratamentos com aplicação da água do são Francisco $+100 \%$ da fertilização, demonstrando a viabilidade técnica do reuso como componente do sistema de produção do pimentão. Duarte (2006), avaliando o efeito da aplicação de água residuária tratada durante o ciclo do pimentão, enfatizou a eficiência do reuso de água residuária tratada com a obtenção de um incremento de $60 \%$ no rendimento de frutos irrigados com essa água, quando comparados ao rendimento obtido nos frutos irrigados com água potável.

Com exceção do tratamento água residuária $+50 \%$ da fertilização, sob manejo baseado na tensiometria, os demais apresentaram produtividade total dentro da faixa da realidade agrícola nacional, que varia entre 20 e $35 \mathrm{t} \mathrm{ha}^{-1}$, conforme descrito por Sousa (2006), estando os resultados apresentados na tabela 3.

Na tabela 3 verifica-se, ainda, que as duas estratégias de irrigação promoveram produtividade total similar; todavia, em função da menor lâmina de irrigação aplicada, o uso da tensiometria promoveu maior eficiência no uso da água (EUA), esta última representando a quantidade de matéria fresca produzida, em função do volume de água aplicado.

Tabela 3. Análise de produtividade total, lâmina total e eficiência do uso da água (EUA)

\begin{tabular}{lccc}
\hline Tratamentos & $\begin{array}{c}\text { Produtividade total } \\
\mathrm{tha}^{-1}\end{array}$ & $\begin{array}{c}\text { Lâmina total } \\
\mathrm{mm}\end{array}$ & $\begin{array}{c}\text { EUA } \\
\mathrm{Kg} \mathrm{ha}^{-1} \mathrm{~mm}^{-1}\end{array}$ \\
\hline ASF+100\% - Hidrofarm & $22.05 \mathrm{a}$ & 424,2 & $51,99 \mathrm{~b}$ \\
AFS+100\% - Tensiômetro & $20,41 \mathrm{a}$ & 358,8 & $56,90 \mathrm{a}$ \\
AR+50\% - Hidrofarm & $22,04 \mathrm{a}$ & 424,2 & $51,95 \mathrm{~b}$ \\
AR+50\% - Tensiômetro & $19,15 \mathrm{a}$ & 358,8 & $53,38 \mathrm{a}$ \\
AR - Hidrofarm & $21,40 \mathrm{a}$ & 424,2 & $50,45 \mathrm{~b}$ \\
AR - Tensiômetro & $21,59 \mathrm{a}$ & 358,8 & $60,17 \mathrm{a}$ \\
\hline CV $\%)$ & 12.09 & & 12.12 \\
\hline
\end{tabular}

Para o consumo total de água durante o experimento, observou-se uma diferença entre as metodologias de manejo de irrigação avaliadas (tabela 3). O manejo da irrigação, com o uso da sonda hidrofarm, resultou em uma lâmina de água superior ao manejo por tensiometria, com um total de $169 \mathrm{~L} \mathrm{planta}^{-1}$, já a tensiometria resultou na aplicação de $143 \mathrm{~L} \mathrm{planta}^{-1}$, ao longo do experimento.

Oliveira (2012), estudando o consumo hídrico do pimentão, sob aplicação de diferentes manejos da fertirrigação, obteve uma demanda hídrica de $170 \mathrm{~L} \mathrm{planta}^{-1}$ o que corrobora os resultados obtidos no presente experimento. Segundo Marouelli e Silva (2012), a necessidade hídrica total do pimentão varia entre 450 e $650 \mathrm{~mm}$, dependendo especialmente das condições climáticas, ciclo de produção, sistema de produção e irrigação adotados.

Na tabela 4, está apresentada a análise de variância e teste de médias das variáveis: produtividade comercial e características físicas de pós-colheita.

Tabela 4. Teste de médias das variáveis: produtividade comercial, massa média, comprimento, diâmetro e a relação comprimento/diâmetro dos frutos

\begin{tabular}{lccccc}
\hline Fonte de Variação & Produtividade comercial & Massa média de frutos & Comprimento & Diâmetro & Relação Comp./Diam. \\
\hline Qualidades de água & $\left(\mathrm{t} \mathrm{ha}^{-1}\right)$ & $(\mathrm{g})$ & $(\mathrm{mm})$ & $(\mathrm{mm})$ & \\
\hline $\begin{array}{l}\text { Água do São Francisco }+ \\
\text { 100\% fertilização }\end{array}$ & $19.47 \mathrm{a}$ & $84.95 \mathrm{a}$ & $125.05 \mathrm{a}$ & $53.35 \mathrm{a}$ & $2.39 \mathrm{a}$ \\
$\begin{array}{l}\text { Água Residuária + 50\% } \\
\text { fertilização }\end{array}$ & $18.76 \mathrm{a}$ & $82.39 \mathrm{a}$ & $122.60 \mathrm{a}$ & $53.67 \mathrm{a}$ & $2.33 \mathrm{a}$ \\
Água Residuária & $19.62 \mathrm{a}$ & $85.98 \mathrm{a}$ & $126.34 \mathrm{a}$ & $54.75 \mathrm{a}$ & $2.35 \mathrm{a}$ \\
\hline Manejos da Irrigação & & & & & \\
\hline Hidrofarm & $19.08 \mathrm{a}$ & $87.33 \mathrm{a}$ & $126.12 \mathrm{a}$ & $53.97 \mathrm{a}$ & $2.38 \mathrm{a}$ \\
Tensiômetro & $19.48 \mathrm{a}$ & $81.55 \mathrm{a}$ & $123.20 \mathrm{a}$ & $53.87 \mathrm{a}$ & $2.33 \mathrm{a}$ \\
\hline $\mathrm{CV}(\%)$ & 5.37 & 12.09 & 5.56 & 5.56 & 6.87 \\
\hline
\end{tabular}

Médias seguidas de mesma letra na coluna não diferem estatisticamente entre si, a 5\% de probabilidade pelo teste de Tukey.

A relação entre produtividade total e comercial obtida para o pimentão, entre os três tratamentos de qualidade de água impostos, mostrou-se similar, tendo o tratamento irrigado com água do São Francisco + 100\% da fertilização, correspondido a
$91,69 \%$ da produtividade total; enquanto que, para os tratamentos irrigados com água residuária tratada doméstica + $50 \%$ da fertilização, e água residuária tratada doméstica, resultaram em $91,12 \%$ e $91,30 \%$ respectivamente, em base 
percentual. Para o manejo da irrigação pela sonda hidrofarm, a produtividade representou $87,43 \%$ da produtividade total, enquanto que, para o manejo por tensiometria, apresentou um valor de 95,59\%. Esse último resultado demonstra o efeito do excesso de água sobre a qualidade dos frutos de pimentão obtidos.

Para os fatores massa média dos frutos (MMF), comprimento do fruto (CP), diâmetro do fruto (DP) e relação comprimento - diâmetro (RCD), a irrigação com diferentes qualidades de água $\mathrm{e}$ os dois manejos de irrigação proporcionaram desempenho agronômico semelhante, o que reforça a viabilidade técnica do reuso de água.

Cavalcante (2008), avaliando o efeito de lâminas de irrigação na produção de pimentão cv Ikeda, obteve um resultado para a variável massa média de frutos de frutos de $21,03 \mathrm{~g}$ e $57,3 \mathrm{~mm}$ e para o comprimento dos frutos, resultados inferiores aos encontrados nesse trabalho. Sousa et al., (2006) também não encontraram diferença para a massa média de frutos de pimentão irrigado com esgoto tratado e água de poço artesiano, em solo com adubação orgânica.
Para Silva (2002), o comprimento e o diâmetro do pimentão são características importantes, pois compõem a definição do seu tamanho e formato, tornando-o atrativo aos consumidores.

Lima et al., (2012), relataram que o comprimento e diâmetro do pimentão cv Konan R não foram estatisticamente influenciados pelos diferentes manejos de irrigação, resultando em um valor médio de $146,8 \mathrm{~mm}$ e $68,3 \mathrm{~mm}$, respectivamente.

No tocante à relação comprimento/diâmetro (RCD), ambos os tratamentos atingiram valores acima de 2. Segundo Charlo et al., (2011), a RCD está relacionada ao formato do fruto. Para os frutos de formato quadrado, a RCD é mais próxima de 1 , já para os frutos alongados, como a cv. Ikeda, resultam em valores superiores a 1 .

Quanto às características químicas de pós-colheita avaliadas, verificou-se diferença significativa para qualidades de água utilizada, nas seguintes características: $\mathrm{pH}$, sólidos solúveis, acidez titulável. Para o fator manejo de irrigação, foi observada diferença apenas na variável $\mathrm{pH}$ (tabela 5).

Tabela 5. Teste de médias das variáveis: $\mathrm{pH}$, sólidos solúveis e acidez titulável

\begin{tabular}{lccc}
\hline Fonte de Variação & $\mathrm{pH}$ & Sólidos Solúveis & Acidez titulável \\
\hline Qualidades de água & & $\left({ }^{\circ}\right.$ brix $)$ & $(\%$ ácido cítrico) \\
\hline Água do São Francisco + 100\% fertilização & $6.13 \mathrm{a}$ & $5.18 \mathrm{a}$ & $0.18 \mathrm{a}$ \\
Água Residuária tratada doméstica + 50\% & $5.70 \mathrm{~b}$ & $4.65 \mathrm{~b}$ & $0.14 \mathrm{~b}$ \\
fertilização & $5.70 \mathrm{~b}$ & $4.35 \mathrm{~b}$ & $0.16 \mathrm{ab}$ \\
Água Residuária tratada doméstica & & & \\
\hline Manejos da Irrigação & $5.72 \mathrm{~b}$ & $4.92 \mathrm{a}$ & $0.16 \mathrm{a}$ \\
\hline Hidrofarm & $5.97 \mathrm{a}$ & $4.59 \mathrm{a}$ & $0.16 \mathrm{a}$ \\
Tensiômetro & 4.37 & 10.8 & 19.17 \\
\hline CV $(\%)$ &
\end{tabular}

Médias seguidas de letras diferentes na vertical diferem entre si, a 5\% de probabilidade, pelo teste de Tukey.

O tratamento irrigado com água do São Francisco $+100 \%$ da fertilização obteve um maior valor de $\mathrm{pH}$, porém os valores médios de $\mathrm{pH}$ obtidos nesse estudo encontram-se na faixa relatada por Damatto (2010), a qual afirma que o $\mathrm{pH}$ do pimentão alcança 6,5 no fruto imaturo, tendendo a reduzir com o amadurecimento, alcançado até 5 no fruto maduro.

Evangelista et al., (2008) encontraram valores de $\mathrm{pH}$ que variaram de 4,7 a 5,9 em pimentões minimamente processados. Corrêa et al., (2014), estudando frutos de pimentão de linhagens e híbridos, submetidos a diferentes temperaturas de armazenamento, obtiveram valores semelhantes aos encontrados nesse trabalho, resultando em um pH médio de 6,2.

$\mathrm{O}$ alto valor do $\mathrm{pH}$, em ambos os tratamentos, pode estar relacionado à concentração do potássio na água, seja na composição, que é o caso da água residuária ou na adição de fertilizantes, como na água do São Francisco. O acúmulo de íons de $\mathrm{K}^{+}$nos frutos resulta na troca catiônica com íons $\mathrm{H}^{+}$, ocorrendo assim, a elevação do pH dos frutos (ARAUJO et al., 2012).

Vásquez et al., (2005) também observou um feito do aumento linear do $\mathrm{pH}$ dos frutos de melão, fertirrigados com diferentes doses de potássio.

Quanto aos manejos da irrigação, uma menor aplicação de água resultou em um maior valor de $\mathrm{pH}$ para os tratamentos irrigados com base na tensiometria, como resultado da elevação no teor de sólidos solúveis, valor semelhante ao encontrado por Silva (2016), que observou um aumento no valor de $\mathrm{pH}$ em melões com menor aplicação de água.

Para o teor de sólidos solúveis (SS), pode-se observar que os tratamentos irrigados com água do São Francisco $+100 \%$ da fertilização resultou em um maior ${ }^{\circ}$ brix (tabela 5). Resultado semelhante ao encontrado por Rinaldi et al., (2013) trabalhando com diferentes qualidades de água, que obtiveram um maior valor de sólidos solúveis em plantas irrigadas com água de córrego, quando comparado aos tratamentos irrigados com efluente tratado de abate de bovinos. Rinaldi et al., (2008), avaliando as características físico-químicas e nutritivas de pimentões produzidos em campo e hidroponia, obtiveram um valor médio de 5,295.

De acordo com Raupp et al., (2009), o valor de sólidos solúveis para um fruto, pode ser influenciado por: genética, temperatura, irrigação e adubação, este último fator, neste trabalho, avaliado através das diferentes qualidades de águas utilizadas na irrigação.

Quanto à acidez titulável, observa-se que o tratamento irrigado com água do São Francisco mais adição de fertilizantes foi o que obteve o maior valor de acidez titulável, fato o qual, está relacionado com o amadurecimento dos frutos de 
pimentões. $\mathrm{O}$ teor de nitrogênio presente na água mais a adição desse elemento na fertirrigação ocasionaram um retardamento das reações metabólicas e, consequentemente, da concentração de ácidos orgânicos no fruto.

Resultado semelhante aos encontrados por Silva (2014), que ao avaliar a qualidade de melões submetidos a dosagens de nitrogênio, obtiveram maiores valores de acidez titulável nos tratamentos com a maior dose de nitrogênio aplicado.

Segundo Duarte (2006), o nitrogênio é, para as plantas, um nutriente estimulante de crescimento e, quando contido na solução de irrigação em elevadas concentrações, pode retardar a maturação dos frutos.

\section{CONCLUSÕES}

A produtividade e características físicas dos frutos de pimentão não são afetadas pela qualidade de água da irrigação.

A fertirrigação proporciona valores superiores dos parâmetros químicos nos frutos de pimentão.

O menor volume de reposição de água, quantificado pela tensiometria, proporciona maior eficiência no uso da água.

\section{REFERÊNCIAS}

AL-ASADI, R. A.; MOUAZEN, A. M. Combining frequency domain reflectometry and visible and near infrared spectroscopy for assessment of soil bulk density. Soil \& Tillage Research v.135, p, 60-70, 2014.

ALMEIDA, O.A. Qualidade da água para irrigação. Embrapa Mandioca e Fruticultura, 2010. 234p.

ARAÚJO, H. S.; QUADROS, B. R. de; CARDOSO, A. I. I.; CORRÊA, C. V. Doses de potássio em cobertura na cultura da abóbora. Pesquisa Agropecuária Tropical, v.42, p.469-475, 2012. http://dx.doi.org/10.1590/S1983-40632012000400004

BRITO, A. S.; LIBARDI, P.L.; MOTA, J.C.A.; MORAES, S.O. Desempenho do tensiômetro com diferentes sistemas de leitura. Revista Brasileira de Ciência do Solo, v. 33, p. 17-24, 2009.

CAVALCANTE, R. R. R. Diferentes lâminas de água e doses de nitrogênio na produção de pimentão. 2008. 58f. Dissertação (Mestrado em Agronomia) - Departamento de Engenharia Agrícola, Universidade federal do Ceará, Fortaleza. 2008.

CEAGESP. Norma de Classificação do Pimentão Para o Programa Brasileiro para a Melhoria dos Padrões Comerciais e Embalagens De Hortigranjeiros. Disponível http://www.alimentares.com/pimentas/_file/noma_pimentoes.pd f>. Acesso em: 21 julho 2018.

CHARLO, H. C. O.; OLIVEIRA, S. F.; CASTOLDI, R.; VARGAS, P. F.; BRAZ, L. T.; BARBOSA, J. C. Growth analysis of sweet pepper cultivated in coconut fiber in a greenhouse. Horticultura Brasileira, Brasília, v. 29, n. 3, p. 316323, 2011.
COELHO, E. F.; SILVA, A. J. P.; MIRANDA, J. H. Definição do posicionamento de sensores para monitoramento da água no solo em bananeira irrigada por diferentes sistemas de irrigação localizada. Engenharia Agrícola, v.30, n.4, p.608-618, 2010.

CORRÊA, S. C. Predição da aceitação sensorial de frutas por meio de parâmetros físicos e físico-químicos utilizando modelo multivariado. 2014. 61f. Dissertação (Mestrado em Ciência dos Alimentos) - Universidade Federal de Lavras, Lavras, 2014.

DAMATTO JR, E.R.; GOTO, G.; RODRIGUES, D.S.; VIVENTINI, M.; CAMPOS, A.J.D. Qualidade de pimentões amarelos colhidos em dois estádios de maturação. Revista Cientifica Eletrônica de Agronomia, v.17, p.23-30, 2010.

DUARTE, A. S. Reuso de água residuária tratada na irrigação da cultura do pimentão (Capsicum annun L.). 2006. 187f. Tese de Doutorado (Doutorado em Agronomia) - Área de concentração em Irrigação e Drenagem, Escola Superior de Agricultura "Luiz de Queiroz", Universidade de São Paulo, Piracicaba, 2006.

EVANGELISTA, R. M.; Godoy, A. R.; CARDOSO, A. I. I. VIEITES, R. L. Qualidade de pimentão 'rubia' minimamente processado e armazenado sob refrigeração. Revista Ceres, v.55, p.338- 343, 2008.

FILHO, E. G.; NAKATANI, J. K.; PINTO, M. J. A.; NEVES, M. F.; CASERTA, P. G.; KALAKI, R. B.; GERBASI, TÁSSIA. Mapeamento e quantificação da cadeia produtiva das hortaliças. Brasília: Markestrat, 2017. 79f.

GOTO, R.; ROSSI, F. Cultivo de pimentão em estufa. Viçosa: CPT, 1997. 66p.

LIMA, E. M. C.; MATIOLLI. W.; THEBALDO, M. S. REZENDE, F. C.; FARIA, M. A. Produção de pimentão cultivado em ambiente protegido e submetido a diferentes lâminas de irrigação. Revista Agrotecnologia, v. 3, n. 1, p. 4056, 2012.

MAROUELLI, W. A.; SILVA, L. C. W. Irrigação na cultura do pimentão. Brasília, DF: Embrapa Hortaliças, 2012. 20 p. (Embrapa Hortaliças. Circular técnica, 101).

OLIVEIRA, F. A. Cultivo do pimentão em ambiente protegido utilizando diferentes manejos de Fertirrigação. 222f. Tese (Doutorado). Escola Superior de Agricultura "Luiz de Queiroz" - Universidade de São Paulo - Piracicaba, 2012.

QUEIROZ, S. O. P. Métodos para avaliação de salinização do solo sob condições de ambiente protegido. 2004. 101f. Tese de Doutorado (Doutorado em Engenharia Agrícola) Universidade Estadual de Campinas, Campinas. 2004.

RAUPP, D. S.; GARDINGO, J. R.; SCHEBESKI, L. S. dos; AMADEU, C. A.; BORSATO, A.V. Processamento de tomate seco de diferentes cultivares. Acta Amazônica, Manaus, v.39, n.2, p.415-422, 2009. 
RINALDI, M. M.; THEBALDI, M. S.; ROCHA, M. S.; SANDRI, D.; FELIZBERTO, A. B. Qualidade pós-colheita do tomate irrigado por diferentes sistemas de irrigação e qualidades de água. Irriga, Botucatu, v. 18, 59-72 p. 2013.

RINALDI, M. M.; SANDRI, D.; RIBEIRO, M. O.; AMARAL, A. G. Características físico-químicas e nutricionais de pimentão produzido em campo e hidroponia. Ciência e Tecnologia de Alimentos, Campinas, v.28, n. 3, p.558-563, 2008.

SANTOS, I. M. S. Manejos de irrigação para produção de pimentão em substratos agrícolas. 2015. 84p. Dissertação (Mestrado em Horticultura Irrigada) Universidade Estadual da Bahia, Juazeiro. 2015.

SHAER-BARBOSA, M.; SANTOS, M. E. P.; MEDEIROS, Y. D. P. Viabilidade do réuso de água como elemento mitigador dos efeitos da seca no semiárido da Bahia. Ambiente e Sociedade, v. 17, n. 2, p. 17-32, 2014. http://dx.doi.org/10.1590/S1414-753X2014000200003

SILVA, F. de A. S. ASSISTAT versão 7.5 beta. Campina Grande: DEAG/CTRN/UFCG, 2008.

SILVA, L. L. Heterose e capacidade de cominação em cruzamentos dialélicos parciais de pimentão. 2002. $82 \mathrm{f}$. Dissertação de Mestrado. Universidade de São Paulo, Piracicaba. 2002.
SILVA, M. C.; SILVA, T. J. A.; BONFIM-SILVA, E. M.; LORRAINE, N. F. Características produtivas e qualitativas de melão rendilhado adubado com nitrogênio e potássio. Revista Brasileira de Engenharia Agrícola e Ambiental, Campina Grande-PB, v. 18, n. 6, p. 581-587, 2014. http://dx.doi.org/10.1590/S1415-43662014000600003.

SILVA, V. D. D. A. Produção de melão sob diferentes qualidades de água e estratégias de irrigação. 2016. 78 p. Dissertação (Mestrado em Horticultura Irrigada) Universidade Estadual da Bahia, Juazeiro. 2016.

SOUSA, J. T.; CEBALlOS, B. S. O.; HENRIQUE, I. N.; DANTAS, J. P.; LIMA, S. M. S. Reúso de água residuária na produção de pimentão (Capsicum annuum L.) Revista Brasileira de Engenharia Agrícola e Ambiental, Campina Grande, v.10, n. 1, p. 89-96, 2006.

TERRA, V. S. S. Avaliação e quantificação dos componentes do balanço hídrico em pomar de pessegueiro, cv. Maciel, em plantas irrigadas e não irrigadas. 2010. 82f. Dissertação de Mestrado. Universidade Federal de Pelotas, Pelotas. 2010.

VÁSQUEZ, M. A. N.; FOLEGATTI, M. V.; DIAS, N. DA S.; SOUSA, V. F. Qualidade pós-colheita de frutos de meloeiro fertirrigado com diferentes doses de potássio e lâminas de irrigação. Revista Brasileira de Engenharia Agrícola e Ambiental, v.9, n.2, p.19-204, 2005. http://dx.doi.org/10.1590/S1415-43662005000200008. 